\title{
Poetry Musicalisation in Teaching BIPA
}

\author{
Budi Agung Sudarmanto ${ }^{1}$, Tri Wahyono ${ }^{2}$, Dian Susilastri ${ }^{3}$ \\ ${ }^{1,3}$ Balai Bahasa Sumatera Selatan, Indonesia, \\ ${ }^{2}$ Universitas Muhammadiyah Yogyakarta, Indonesia \\ 1budi.agung@kemdikbud.go.id, 2triwahyono@umy.ac.id \\ ${ }^{3}$ dian.susilastri@kemdikbud.go.id
}

\begin{abstract}
Indonesian Goverment is vigorously carrying out the program of BIPA teaching. BIPA teaching constitutes the embodiment of the mandate of implementation of Indonesian Republic regulation No. 24 Year 2009 about Flag, Language, Nation Symbols, and National Anthem, especially Article 44, namely enacting Indonesian language as the international language. This BIPA teaching is not only implemented in domestic but also in overseas. Indonesian government has carried out BIPA teaching in almost all of continents in the world. Therefore, related to this BIPA teaching, approaches, methods, strategies, and techniques have been also already applied. One of the offerings to enrich the BIPA teaching technique is poetry musicalisasion. Research method used is qualitative by functioning library study. The steps of poetry musicalisasion are choosing, reading, understanding, and interpreting poetry, determining rhytm, determining composition, and arranging composition. The literature, that is poetry, becomes the main dominantly point. There is element of creativity, locality, beauty, and also harmony produced from this poetry musicalisation. Being expected from poetry musicalisation in BIPA teaching is that BIPA learners get to know about Indonesian culture. Teaching BIPA also instructs Indonesian cultures, beside Indonesian language.
\end{abstract}

Keywords: BIPA, poetry, musicalization

\section{PENDAHULUAN}

Pemerintah Indonesia mengupayakan bahasa Indonesia menjadi salah satu bahasa yang dikenal dan disegani di kancah internasional. Undang-Undang Nomor 24 Tahun 2009 tentang Bendera, Bahasa, dan Lambang Negara, serta Lagu Kebangsaan, terutama pada Pasal 44, menjadi landasan penginternasionalan bahasa Indonesia tersebut. Upaya pemerintah Indonesia, salah satunya, dilakukan dengan pengajaran bahasa Indonesia bagi penutur asing yang biasa dikenal dengan BIPA.

Di dalam pengajaran BIPA berbagai upaya pendekatan, metode, strategi, dan model, serta teknik pengajaran BIPA bisa dilakukan. Pendekatan bisa dilakukan dengan student centered approach [1] dan teacher centered approach [2]. Wortham [3] mengemukakan pentingnya metode pembelajaran konvensional dan modern sekaligus. Dari kedua metode pembelajaran ini menghasilkan metode pembelajaran yang taktis, teknis, dan praktis. Dari sini dihasilkan metode ekspositori, metode demonstrasi, metode diskusi panel, debat, metode bermain peran, dan metode simulasi. Dengan demikian, metode konvensional dan modern tersebut menjadi 
metode yang sangat menunjang di dalam pembelajaran. Strategi pembelajaran dilakukan dengan ekspositori, inkuiri, CTL (Contextual Teaching and Learning), dan sebagainya [4]. Bruce, Weril, dan Calhoun [5] mengetengahkan 4 (empat) kelompok model pembelajaran. Keempat model pembelajaran tersebut adalah model proses informasi (information processing), kepribadian humanistik (personal-humanistic), hubungan kemasyarakatan (social interaction), dan perubahan perilaku (behaviour modification).

Untuk mengetahui kemampuan berbahasa, termasuk kemampuan BIPA seseorang, salah satu parameter yang dipergunakan adalah Common European Framework of Reference fo Language (CEFRL). Standar pemeringkatan ini menggunakan tiga jenjang dasar yaitu Basic, Independent, dan Proficient. Masing-masing jenjang ini terdiri dua kelompok lain, yaitu jenjang Basic terdiri atas A1 dan A2, Independent terdiri atas B1 dan B2, dan Proficient terdiri atas C1 dan C2 [6]. Salah satu tawaran pengajaran yang bisa dilakukan di dalam BIPA dengan menggunakan musikalisasi puisi. Mungkin sepintas ini terlihat sulit dan berat. Pertama, sastra adalah lapis kedua (second layer) dari bahasa [7]. Kedua, tentang genre sastra yang dipilih, yaitu puisi yang memiliki tingkat kemampuan pemahaman yang lebih tinggi dibandingkan dengan dua genre sastra yang lain yaitu prosa dan drama. Ketiga, musikalisasi dari puisi yang dijadikan medium untuk mengapresiasi genre sastra puisi yang dipilih. Dibutuhkan talenta di bidang musik dan vokal untuk bisa merealisasikan pembelajaran musikalisasi puisi ini di dalam BIPA. Akan tetapi, banyak hal positif dan menarik di dalam pengajaran musikalisasi puisi ini di dalam pengajaran BIPA.

Pengertian mengenai puisi berasal dari bahasa Yunani yaitu poeima yang bermakna "membuat". Istilah puisi juga berasal dari kata poesis yang bermakna"pembuatan". Dengan demikian, puisi bisa dimaknai sebagai "membuat" atau "pembuatan" sesuatu, yaitu semacam pembuatan dunia tersendiri, oleh seseorang yang menciptakannya. Aminudin [8] menyebut hasil ciptaan ini bisa berisi pesan atau gambaran suasana-suasana tertentu baik fisik maupun psikis (batiniah). Lebih lanjut, Sayuti [8] menyatakan bahwa puisi adalah sebentuk pengucapan bahasa yang memperhitungkan adanya aspek bunyi-bunyi di dalamnya. Dengan kata lain, puisi adalah cara menyampaikan unsur kebahasaan yang dipengaruhi oleh unsur nada atau laras yang membangunnya. Puisi juga mengungkapkan pengalaman dunia khayal yang imajinatif, menyentuh perasaan, kemampuan kecerdasan seseorang dengan lingkungannya yang diuraikan dengan suatu cara tertentu. Dengan demikian, puisi mampu menghidupkan suatu nuansa pengalaman batin tersendiri bagi pembaca atau pendengar puisi tersebut. Menurut Santosa [9], puisi merupakan genre sastra yang menjadi peristiwa kebahasaan yang tersaring begitu murni dalam mengekspresikan kepribadian dalam suatu bentuk yang selaras dengan watak yang diungkapkannya. Untuk memahami puisi perlu dilakukan apa yang biasa disebut dengan apresiasi.

Apresiasi puisi dapat dilakukan dengan cara deklamasi, baca puisi, baca puisi diiringi musik, dan musikalisasi puisi [10]. Deklamasi adalah mengapresiasi puisi dengan mengucapkan langsung tanpa membaca dari sumber puisi yang ada. Deklamasi puisi terkesan menghafalkan bait-bait dari puisi yang diapresiasinya. Baca puisi adalah mengapresiasi puisi dengan cara membaca dari teks puisi yang ada. Baca puisi diiringi musik adalah bentuk apresiasi sebuah puisi dengan pembacaan yang diselingi atau diiringi musik. Ini adalah dua jenis kegiatan yang berdeda, satu membaca yang lainnya mengiringi. Musikalisasi puisi adalah penggabungan unsur sastra (puisi) dengan musik dan vokal secara bersama-sama. Di dalam pengajaran BIPA masing-masing jenis apresiasi puisi ini bisa diajarkan. Tulisan ini akan membahas musikalisasi puisi sebagai teknik pengajaran BIPA.

Salad [11] mengatakan bahwa musikalisasi puisi adalah bentuk penyampaian ungkapan seni sastra (puisi) dan seni musik. Kedua jenis seni ini saling melengkapi di dalam 
kebersamaan dengan sastra puisi sebagai ujung tombaknya. Musikalisasi puisi bisa dimainkan di dalam suatu panggung pertunjukan, festival, lomba, atau sarana yang lain. Sumiyadi dan Durachman [12] menyatakan bahwa musikalisasi puisi adalah menjadikan sajak menjadi sebuah irama lagu. Lirik (syair) puisi dihadirkan atau muncul terlebih dahulu sebelum aransemen musik dihadirkan untuk mengiringi ciri atau watak dari puisi tersebut. Syair puisi tersebut digubah menjadi irama lagu yang berkarakter. Keberadaan puisi merupakan satu kesatuan yang tidak bisa diubah-ubah.

Musikalisasi puisi sebagai sebuah sarana apresiasi menarik perhatian para pemerhati dan/atau pelaku sastra, khususnya genre puisi. Koapaha, dkk. [13] membahas apresiasi terhadap sajak yang berjudul "Hatiku Selembar Daun" karya Sapardi Djoko Damono dalam bentuk musikalisasi puisi. Selain itu, pada tingkat sekolah menengah atas, Okaria [14] juga melakukan penelitian terhadap pengerjaan musikalisasi puisi Di Beranda karya R. Giryadi yang dilakukan oleh SMAN 2 Bangkalan. Masing-masing penelitian tersebut tidak membicarakan dengan terinci tentang bahagaimana pelaksanaan penerapan musikalisasi puisi yang dilakukannya. Upaya untuk menampilkan nuansa kelokalan belum terlihat. Selain itu, semua penelitian tersebut belum ada yang menyinggung tentang penerapannya di dalam pengajaran BIPA. Tulisan ini mengisi rumpang yang belum mereka isi.

Musikalisasi puisi layak dijadikan sebagai teknik pembelajaran BIPA. Ini adalah sebuah upaya terobosan yang bagus bagi apresiasi puisi-maupun memberi pemahaman bagi pembelajar BIPA atas keanekaragaman yang ada di negeri Indonesia ini. Berdasarkan latar belakang tersebut, masalah yang muncul, yaitu bagaimanakah penerapan metode pembelajaran BIPA menggunakan materi musikalisasi puisi? Bagaimanakah hasil yang diharapkan dengan penerapan metode pembelajaran BIPA dengan materi musikalisasi puisi? Untuk alasan itulah penelitian ini layak untuk dilakukan.

\section{METODE PENELITIAN}

Penelitian ini menggunakan studi kepustakaan. Mardalis [15] menyampaikan bahwa studi kepustakaan adalah suatu kajian yang memanfaatkan segala sesuatu terkait kepustakaan seperti literatur, buku, dokumen, majalah, dan bahan-bahan lain sebagai informasi dan data yang dipakai di dalam penelitian. Selanjutnya, Sugiyono menyatakan bahwa arah penelitian studi kepustakaan berhubungan dengan norma, budaya, dan nilai dari suatu kondisi masyarakat yang sedang diteliti [16]. Di dalam penelitian yang berbasis studi kepustakaan, data dikumpulkan dengan menggunakan teknik dokumentasi. Pendokumentasian dilakukan atas data yang dibutuhkan. Data yang dikumpulkan berasal dari buku referensi, makalah, jurnal, artikel, majalah ilmiah, laporan penelitian, dan sebagainya [17]. Dari masing-masing data tersebut, selanjutnya, dilakukan pembahasan dan penerapan metode/tahap-tahap proses pembelajaran dengan musikalisasi puisi di dalam pengajaran BIPA.

\section{HASIL DAN PEMBAHASAN}

Common European Framework of Reference for Language (CEFRL) [6] menjadi standar yang digunakan untuk menggambarkan pencapaian para pembelajar bahasa asing di seantero Eropa. Standar ini juga bisa dijadikan sebagai acuan di dalam pengajaran BIPA. Dari standar CEFRL tersebut bisa dirujuk posisi kemampuan pembelajar untuk bisa menerima pembelajaran musikalisasi puisi. Setidaknya pembelajar diharapkan sudah berada di dalam level Proficient (B1) dengan kriteria: (a) dapat memahami atau mengerti secara sungguh berbagai teks. Teksnya bisa panjang dan sulit. Pembelajar dapat mengenali makna implisit 
yang ada; (b) dapat mengungkapkan keberadaan diri sendiri dengan baik dan serta merta. Pembelajar tidak mengalami banyak kesulitan untuk menemukan ekspresi yang benar; (c) penggunaan fleksibilitas dan efektivitas bahasa untuk keperluan kehidupan sehari-hari, akademis, dan sesuai dengan profesi yang diemban; dan (d) mampu memproduksi teks tentang topik sulit. Pembelajar bisa menggunakan bahasa yang bersangkutan dengan jelas, terstruktur, dan terperinci. Produksi teks yang dihasilkan memperlihatkan susunan kalimat, tanda hubung yang tepat, dan kekohesifan yang baik. Hal ini bisa dipahami karena jenis pembelajaran ini adalah sastra, sebagai lapis kedua dari bahasa [17].

Musikalisasi puisi adalah cara lain di dalam upaya untuk mengapresiasi puisi selain deklamasi, membaca, dan membaca puisi diiringi musik. Khrais [18] merujuk konsep Jonathan Culler tentang "naturalisasi" di dalam apresiasi puisi. Yaitu, memahami dan mengapresiasi suatu puisi secara natural dengan menggunakan sarana musik beserta alat-alat musik pendukungnya. Dengan musikalisasi puisi, secara natural, apresiasi puisi untuk bisa menghayati dan memahaminya bisa dilakukan dengan baik. Di dalam musikalisasi puisi, pada dasarnya, adalah membicarakan dua ranah yang berbeda, yaitu puisi sebagai bagian dari (seni) sastra di satu sisi dengan musik di bagian lainnya. Allis [19] menyitir pendapat yang disampaikan oleh Steven Paul Scher tentang kaitan antara musik dengan sastra. Menurutnya ada tiga relasi di antara keduanya, yaitu sastra adalah peniruan dari ...kualitas musik akustik, adaptasi yang lebih besar dari struktur dan pola musik dan aplikasi dari teknik dan alat atau sarana musik tertentu, dan presentasi penyajian sastra ...adalah komposisi musik yang nyata dan tidak nyata. Ini artinya bahwa keberadaan sastra pun, di dunia musik, juga sudah mendapat perhatian semenjak lama.

Adanya relasi di antara sastra, puisi dalam hal ini, dengan musik memerlukan adanya transfer media di antara keduanya. Seperti yang disampaikan oleh Dipayana [10], puisi adalah syarat utama di dalam pelaksanaan musikalisasi puisi. Artinya, perlu ditentukan puisi terlebih dahulu sebelum melakukan musikalisasi. Ellestrom [20] menyarankan adanya media transformasi antara dua ranah, puisi dan musik, ini. Alleston menyebutkan mediation dengan representation. Hal ini dimaksudkan untuk menemukan makna dari data media yang tersedia. Yang harus dilakukan di dalam media transformasi ini adalah memahami karakteristik di antara keduanya. Dengan demikian, puisi sebagai sumber data media perlu diberi mediasi melalui musik untuk menemukan representasi berupa pemahaman makna yang terkandung di dalam puisi tersebut.

Pelaksanaan pembelajaran musikalisasi puisi untuk pembelajar BIPA tentu tidak akan sama dengan pembelajaran tersebut diterapkan kepada pembelajar reguler yang menggunakan bahasa Indonesia sebagai bahasa pertamanya. Di dalam melaksanakan pembelajaran musikalisasi puisi, terutama bagi pembelajar BIPA, Prawiyogi dan Cahyani [11] menyarankan untuk melakukannya dalam tiga tahapan. Ketiga tahapan tersebut adalah persiapan (conditioning), pelaksanaan, dan perefleksian.

Di dalam melakukan musikalisasi puisi diperlukan beberapa kemampuan baik di dalam bidang sastra (puisi) dan musik (termasuk olah vokal). Perpaduan antara seni sastra (puisi) dan seni musik, dengan puisi sebagai faktor utamanya, akan menghasilkan apresiasi puisi yang lebih bermakna. Salad [11] menyatakan bahwa musikalisasi puisi tidak mungkin terlaksana tanpa adanya puisi. Untuk sampai pada tahapan itu, Dipayana [10] memberikan penjelasan tentang tahapan di dalam pelaksanaan musikalisasi puisi, yaitu memilih puisi, membaca dan memahami puisi, menafsirkan puisi, menentukan irama, menciptakan harmoni, dan mengaransemen komposisi.

Puisi yang sudah dipilih, selanjutnya, mulai dibaca. Pembacaan ini perlu dilakukan secara berulang-ulang untuk mendalami dan semakin memahami kandungan yang ada di dalam puisi 
yang akan dijadikan musikalisasi puisi. Pada tahapan ini mulai dikenali kata-kata yang membentuk keseluruhan puisi. Apabila ada kosakata yang sekiranya masih tidak atau belum dipahami bisa didiskusikan dengan sesama pembelajar, atau dengan gurunya. Pemahaman terhadap keseluruhan puisi akan sangat membantu untuk masuk ke tahapan berikutnya.

Menafsirkan atau menginterprestasi puisi menjadi tahapan yang sangat penting di dalam apresiasi puisi, termasuk musikalisasi puisi. Kemampuan menafsirkan kandungan puisi menjadi kunci keberhasilan di dalam melakukan musikalisasi puisi. Di dalam penafsiran inilah kita akan menemukan roh dari makna dalam yang tersimpan di dalam puisi. Ideologi tertentu yang terpendam di dalam puisi bisa ditemukan melalui proses penafsiran yang baik. Tahapan selanjutnya adalah menentukan irama. Puisi sebenarnya sudah memiliki basis irama di dalamnya. Apabila dilakukan musikalisasi puisi maka unsur irama, pada dasarnya, sudah ada di dalam puisi tersebut. Pada gilirannya, irama tersebut harus ditemukan sebelum dipadupadankan dengan irama musik lain yang ada di luar puisi yang sudah dipilih. Pada tahapan ini unsur musik sudah mulai berperan. Mulai perlu juga diperhatikan sinkronisasi antara kandungan puisi yang ada (sebagai hasil dari interpretasi yang sudah dilakukan) dengan irama musik yang dikomposisikan. Perlu diperhatikan juga jenis alat musik yang akan dimanfaatkan di dalam melakukan musikalisasi puisi.

Menciptakan komposisi atas puisi yang akan dijadikan bahan musikalisasi puisi bisa dilakukan setelah irama yang ada di dalam puisi ditemukan. Setelah itu, irama di dalam puisi tersebut (metrum) dipadupadankan dengan irama musik yang akan dipakai untuk musikalisasi puisi. Pada tahapan ini sudah perlu diperhatikan komposisi yang akan bisa mewakili kandungan puisi yang dipilih. Komposisi yang dipersiapkan bisa ceria, gembira, sedih, melankolis, bersemangat, dan sebagainya. Tahapan akhir adalah mengaransemen komposisi musik. Olah vokal dan pemilihan alat musik menjadi bagian yang sangat penting di dalam musikalisasi puisi. Di dalam musikalisasi puisi, unsur yang terkait dengan kelokalan menjadi menarik. Untuk pengajaran BIPA unsur kelokalan nusantara menjadi penting untuk lebih memperkenalkan keanekaragaman Indonesia. Memperkenalkan alat musik tradisional Indonesia adalah salah satunya.

Untuk melengkapi tahapan musikalisasi puisi diperlukan interpretasi, kreativitas, vokal, komposisi musik, penampilan, dan lokalitas. Seperti sudah disampaikan sebelumnya, interpretasi atau penafsiran terhadap puisi menjadi kunci keberhasilan di dalam upaya memahami puisi yang akan dijadikan musikalisasi. Hasil interpretasi ini bisa dikatakan bahwa puisi itu berbicara tentang kesedihan, kegembiraan, keceriaan, penderitaan, kehilangan, dan sebagainya.

Musikalisasi puisi membutuhkan kreativitas. Semakin kreatif akan semakin indah tampilan musikalisasi puisi yang dihasilkan. Kreativitas ini bisa dilakukan saat melakukan interpretasi puisi, selain alat musik yang dipakai, komposisi musik yang dilakukan, vokal, penampilan, dan sebagainya. Musikalisasi puisi, terkait dengan kreativitas, tidak mengenal plagiasi atau peniruan atas apa pun yang pernah dilakukan oleh orang lain. Semakin orisinal karya musikalisasi puisi yang dihasilkan semakin baik bagus musikalisasi puisi tersebut. Diperlukan harmonisasi di antara puisi, interpretasi, musik, dan vokal yang akan ditampilkan. Sumbang dan ketimpangan merupakan hal yang harus dihindari. Harmoni juga perlu dilakukan di dalam komposisi musik. Kreativitas yang tinggi tetap harus disesuaikan dengan interpretasi terhadap puisi, tidak boleh menyimpang dari interpretasi yang sudah dihasilkan. Penampilan menjadi hal yang penting. Hasil apresiasi puisi melalui musikalisasi puisi perlu untuk ditampilkan. Penampilan adalah bagian paling akhir dari rangkaian musikalisasi puisi. Unsur kreativitas yang lain, termasuk ekspresi dan kostum menjadi bagian yang menentukan di dalam 
musikalisasi puisi. Masing-masing dimaksudkan untuk mendukung harmoni dari interpretasi puisi dilakukan.

Di dalam musikalisasi puisi, unsur kelokalan menjadi faktor yang sangat penting. Salah satu kelokalan yang bisa ditampilkan di dalam pembelajaran BIPA adalah alat musik tradisional. Indonesia memiliki banyak alat musik tradisional yang tersebar dari Sabang sampai Merauke. Bagi pembelajar BIPA, alat musik tradisional ini akan memperkaya pengetahuan mereka terhadap negeri Indonesia. Hampir semua provinsi di seluruh Indonesia memiliki alat musik tradisional tersebut. Hal ini menambah khazanah pemahaman pembelajar BIPA atas Indonesia. Stawiarski [21] menunjukkan pentingnya alat dan nuansa musik tradisional yang mampu membangun ruh puisi. Dia memberi contoh puisi Aiken yang dimusikalisasikan oleh dirinya sendiri dengan menggunakan alat-alat musik tradisional yang menghasilkan nuansa musik yang eksklusif, meski terkesan marjinal, di antara deru dunia modern. Musikalisasi puisi yang dilakukannya, dengan berbasis pada kelokalan dan tradisionalis menjadikan puisi Aiken yang disebutnya sebagai "tradisi dari romantisisme tinggi”, justru menjadi lebih bagus, bernuansa, dan lebih bisa dipahami maknanya. Ini artinya kelokalan di dalam musikalisasi menjadi faktor yang penting. Di dalam pembelajaran BIPA, memperkenalkan kelokalan Indonesia melalui musikalisasi puisi memberi pembelajaran informal bagi pembelajarnya.

Salah satu realisasi penerapan musikalisasi puisi di dalam pengajaran BIPA adalah bagi mahasiswa darmasiswa yang berasal dari Polandia, Tiongkok, Laos, dan Madagaskar yang ada di Universitas Sriwijaya, Palembang. Penerapan musikalisasi puisi di dalam pembejaran BIPA tersebut mendapat tanggapan yang positif. Pembelajar BIPA menjadi lebih bisa mengartikulasikan kosakata bahasa Indonesia dengan lebih baik, memahami isi puisi dengan lebih baik, dan mendapatkan kesenangan kegairahan di dalam menampilkan musikalisasi puisi yang mereka komposisikan. Mereka diberi kesempatan tampil di dalam suatu panggung untuk menampilkan kemampuan musikalisasi puisi yang mereka miliki.

\section{SIMPULAN}

Kegiatan musikalisasi puisi menjadi penawaran yang menarik di dalam metode pembelajaran BIPA. Pembelajar BIPA dengan level kemampuan berbahasa Indonesia yang sudah memadai (Proficient/minimal C1) akan bisa melakukan musikalisasi puisi ini dengan baik. Tahapan penerapan metode tersebut, yaitu pembagian kelas menjadi beberapa kelompok, penentuan jumlah anggota di dalam satu kelompok, pemilihan puisi, pembacaan dan pemahaman puisi, penafsiran puisi, penentuan irama, penentuan vokalis, penciptaan komposisi, pengaransemenan komposisi, dan penampilan. Musikalisasi puisi diharapkan dapat meningkatkan kemampuan di dalam mengapresiasi puisi. Selain itu, kegiatan ini juga akan memberi pengetahuan mengenai keanekaragaman budaya yang ada di Indonesia, salah satunya alat musik tradisional.

\section{REFERENCES}

[1] S. B. Qutoshi and T. Poundel, "Student Centered Apporach to Teaching: What Does It Mean for the Stakeholders of a Community School in Karachi, Pakistan," J. Educ. Res., vol. 4, no. 4, pp. 19-33, 2014.

[2] I. Emaliana, "Teacher-Centered or Student-Centered Learning Approach to Promote Learning?," J. Sos. Hum., vol. 10, no. 2, pp. 59-70, 2017.

[3] E. R. Dewi, "Metode Pembelajaran Modern dan Konvensional pada Sekolah 
Menengah Atas," Pembelajaran J. Ilmu Pendidikan, Keguruan, dan Pembelajaran, vol. 2, no. 1, 2018.

[4] M. S. Hanafy, "Implikasi Penerapan Strategi Pembelajaran dan Perilaku Belajar terhadap Hasil Belajar Peserta Didik di Madrasah Aliyah Madani Paopao Kabupaten Gowa," J. al-Kalam, vol. IX, no. 2, pp. 125-140, 2017.

[5] B. Joyce, M. Weil, and E. Calhoun, Models of Teaching: Model-model Pengajaran. Yogyakarta: Pustaka Pelajar, 2011.

[6] J. H. Hulstijn, "The Common European Framework fo Reference for Languages: A challenge for applied linguistics," ITL Int. J. Appl. Linguist., vol. 165, no. 1, pp. 3-18, 2014.

[7] R. Wellek and A. Warren, Teori Kesusastraan. Jakarta: PT Gramedia Pustaka Utama, 2014.

[8] S. Munika, S. Nasriah, D. Luthfi, and U. A., "Penambahan Kosakata dan Peningkatan Nilai Kehidupan pada Anak Tunarungu melalui Musikalisasi Puisi," PELITA, vol. IX, no. 1, pp. 191-197, 2014.

[9] D. M. Citraningrum, "Menulis Puisi dengan Teknik Pembelajaran yang Kreatif," J. Belajar Bhs., vol. 1, no. 1, pp. 82-90, 2016.

[10] A. A. Dipayana, Panduan Praktis Apresiasi Sastra: Musikalisasi Puisi untuk Sekolah Menengah. Jakarta: Pusat Bahasa, Kementerian Pendidikan Nasional, 2010.

[11] A. G. Prawiyogi and I. Cahyani, "Pengaruh Pembelajaran Musikalisasi Puisi terhadap Kemampuan Membacakan Puisi di Sekolah Dasar," J. Pendidik. ke-SD-an Metod. Didakt., vol. 11, no. 1, pp. 1-7, 2016.

[12] R. M. Ismayani, "Musikalisasi Puisi Berbasis Lesson Study sebagai Alternatif Pembelajaran Inovatif," J. Ilm. Progr. Stud. Pendidik. Bhs. dan Sastra Indones. Semant., vol. 5, no. 2, pp. 1-14, 2017.

[13] R. B. Koapaha, U. Rokhani, and N. Farida, "Musikalisasi Puisi "Hatiku Selembar Daun"," Resital, vol. 10, no. 1, pp. 81-93, 2009.

[14] T. A. Okaria, "Proses Penggarapan Musikalisasi 'Di Beranda' oleh Pelangi SMADA di SMAN 2 Bangkalan," J. Pendidik. Sendratasik, vol. 4, no. 1, pp. 1-20, 2016.

[15] A. M. T. and B. Purwoko, "Studi Kepustakaan Mengenai Landasan Teori dan Praktik Konseling Expressive Writing," J. BK Unesa, vol. 8, no. 1, pp. 1-8, 2018.

[16] Sugiyono, Metode Penelitian Kuantitatif Kualitatif dan $R \& D$. Bandung: Alfabeta, 2012.

[17] S. Arikunto, Prosedur Penelitian: Suatu Pendekatan Praktik. Jakarta: Rineka Cipta, 2010.

[18] S. M. Khrais, “Art and Poetry: The Power of Form,” J. Langugae Lit., vol. 4, no. 2, pp. 106-114, 2013.

[19] M. Allis, "Reading Music through Literature: Introduction," J. Musicol. Res., vol. 36, no. 1, pp. 1-5, 2017.

[20] L. Ellestrom, "Transfer of Media Characteristics among Dissimilar Media," Palabra Clave, vol. 20, no. 3, pp. 663-685, 2017.

[21] M. Stawiarski, "Words and Music Boundaries: Conrad Aiken and his Ambiguous Musicality of Poetry," Comparatismi, vol. II, pp. 83-94, 2017. 